\title{
EDUCAÇÃO E CURRÍCULO: COMO ATENDER A DEMANDA NO CONTEXTO SOCIAL ATUAL
}

\section{ARTIGO DE REVISÃO}

ROCHA, Antônio Carlos da ${ }^{1}$

ROCHA, Antônio Carlos da. Educação e currículo: Como atender a demanda no contexto social atual. Revista Científica Multidisciplinar Núcleo do Conhecimento. Ano 05, Ed. 03, Vol. 05, pp. 61-78. Março de 2020. ISSN: 2448-0959, Link de acesso: https://www.nucleodoconhecimento.com.br/educacao/educacao-e-curriculo

“[...] Não critico a máquina educacional por sua ineficiência. Critico a máquina educacional por aquilo em que ela pretende produzir, por aquilo em que ela deseja transformar nossos jovens [...]" (ALVES, 1994. p 19).

\section{RESUMO}

O presente artigo busca promover reflexão acerca da Educação e Currículo, por essa razão, o tema proposto acima. Espera-se que a educação desperte para a urgente exigência do pragmatismo dos últimos tempos que, evidentemente, continuarão a ampliar no futuro. É necessária e urgente a adequação de um currículo que venha a atender a demanda social desta era globalizada. A humanidade, criativa, capaz de inovar a cada dia "transforma" o contexto social e as transformações geram efeitos positivos, inovadores, mas o risco do oposto, também é evidente. Em função do advento das TDIC[2] da era globalizada a educação está sujeita a fazer ajustes em seu currículo, e, também, em sua didática de ensino. Percebe-se que a atual

\footnotetext{
${ }^{1}$ Mestre em Ciências da Educação (UNADES - Paraguai, 2020). Especialização em Ciências da Educação (FAP-ES, 2016). Especialização em Filosofia da Educação (FAP - ES, 2016). Especialização em Didática e Metodologia do Ensino Superior (UNIOURO - RO, 2009). Licenciatura Plena em Pedagogia (UNIR- RO, 2008). Técnico em Agropecuária (EFA - RO, 2003).
} 
conjuntura instiga a reflexão, tanto nos procedimentos didáticos, quanto na estrutura curricular. Por essa razão, busca-se refletir sobre três assuntos básicos: a família, a educação e o currículo, com o intuito de dar sustentação à pesquisa. Espera-se que este artigo, estudo bibliográfico, possa fomentar o debate que parece ser urgente, mas ainda tímido na educação.

Palavra-Chave: Currículo, conjuntura, educação, inovação.

\section{INTRODUÇÃO}

O tema "Educação e Currículo: Como atender a demanda no contexto social atual" é instigante, visto que a humanidade faz grandes descobertas no decorrer da sua história, em destaque aparece à capacidade de se comunicar, de instruir e ser instruído. Fortalecendo a possibilidade de informar e ser informado, a comunicação que antes era oral, ou visual - no caso das pinturas rupestres e perdurou por muitas gerações, foi ampliada, transformando-se em um contexto gráfico, a escrita, e, isso parece pertinente. A palavra "educação" veio primeiro por se tratar do ato de dialogar, informar e ser informado. Ao preocupar em ensinar e aprender, o setor educacional fez descoberta, ampliou-se, capacitando os envolvidos no processo. As descobertas, exigiram ajustes, algo novo que pudesse facilitar a compreensão das mudanças de comportamento da sociedade. Um desses ajustes é o currículo, a segunda palavra no título do artigo.

No segundo plano, complemento no tema "Como atender a demanda no contexto social atua", há o convite ao leitor para fazer uma reflexão e pensar na atualidade, visa provocar o debate em relação ao projeto educacional com vista a uma adequação para o momento e também para o futuro. Se as grandes corporações[3] criam inovações e constantes transformações, como o quesito tecnologia, evidentemente, a educação e seu processo curricular são convidados a fazerem ajustes para atender e informar a sociedade sobre a nova demanda social. Pensando assim, fica claro que o momento é propício para tal reflexão, porque as transformações no mundo globalizado é uma constante. O mundo da tecnologia de informação, dos projetos tecnológicos em expansão com vista até ao espacial astronômico, e o caos de ordem ambiental 
que o planeta terra enfrenta, mostram que é preciso uma atenção cautelosa da educação para, paralelo a estas inovações, ajudar a sociedade entender o que ela está vivendo.

Não seria bom para a sociedade, nem para as grandes corporações que detêm a tecnologia de informação, menos ainda para a educação, ter projetos educacionais e um currículo inadequado. Atender os cidadãos e inseri-los no mercado de trabalho em um contexto social em transição, sem os ajustes necessários, é um risco. O momento exige atualizações constantes, exige, entender a tecnologia na sua essência como colaboradora e promissora para a sociedade, mas também, entender que se trata de uma inovação que está sujeita a comprometimentos sociais devastadores. Pois ela é ampla e livre aos interesses opostos, trás benefícios e não impede os malefícios.

Enquanto a educação busca atender o local, despertar os cidadãos sobre o comportamento da sociedade, atualizando-se. As grandes corporações que controlam os meios tecnológicos vivem outras dimensões e não tem a mesma preocupação com o local. A primeira deve pensar a curto, médio e longo prazo sobre as influências que o mundo e suas inovações, sejam ela cultural, tecnológica ou ambiental têm sobre o local. A segunda, mesmo pensando a curto, médio e longo prazo, visa o lucro e enxerga sua expansão em âmbito global. É preciso que o cidadão esteja preparado para usufruir dos benefícios tecnológicos, mas acima de tudo, se conscientizar que o sujeito (cidadão), é mais importante do que toda a inovação tecnológica. É preciso saber usar a máquina e evitar ser usado por quem detêm o controle destas inovações. Assim sendo, entra no jogo o diálogo envolvendo a família, o modelo político, o econômico, a globalização e, por fim, a educação e as inovações tecnológicas, que está no tema do artigo.

\section{A FAMÍLIA}

Quando se fala em educação fala-se da reflexão em uma dimensão ampla, portanto, requer do currículo escolar pensar na educação em sua amplitude. É preciso visar entender a realidade das famílias que compõe a comunidade escolar e por essa razão, faz-se necessário a reflexão sobre o tema família. Tomemos como ponto de partida 
as interrogações: O que vem a ser uma família? Qual a sua função na sociedade? O que é um poder público? E o que é um poder privado? Ao serviço de quem estes poderes estão? Ambas são interrogações pertinentes que requerem do leitor e evidentemente da educação muitas reflexões.

Tomemos como ponto de partida a família. Segundo o minidicionário Aurélio (FERREIRA, 2000, p 312) família é: “... pessoas aparentadas que vivem em uma mesma casa, particularmente o pai, a mãe e os filhos.". Neste sentido, sem muito esforço, percebe-se que a família é uma instituição e exige critério, harmonia e trocas de experiências. Ao perceber a família constituída por pai, mãe e filhos, fica explícito que ela caracteriza-se como a matriz geradora dos cidadãos para uma extensão maior, a sociedade. Se a família é a base e onde se aprende a dar os primeiros passos rumo à sociedade, obviamente cabe a ela preparar os filhos para as primeiras relações entre pessoas.

Ao ler uma matéria em que o Papa Francisco falava sobre a família estava a seguinte afirmação: "A revolução nos costumes e na moral muitas vezes abanou a "bandeira da liberdade" e acabou levando devastação espiritual e material a tantas pessoas, especialmente as mais vulneráveis". (MAÇAL, 2016). Muitas famílias estão se preocupando com o modelo de liberdade das gerações contemporâneas, modelo esse, influenciado pelas inovações tecnológicas do mundo globalizado. Entende-se, que, com o passar dos tempos e o aumento da população no planeta terra, novas formas de produção e organização social no âmbito do liberalismo exacerbado, fez com que a estrutura familiar desse lugar a outra forma de organização, alterando em sua essência.

Pensando em melhorar as relações sociais e atender a diversas necessidades, a sociedade "moderna", estruturou seus poderes político e econômico exigindo do público e até do privado muitas transformações. Tais influências trouxeram consigo uma avalanche de problemas de ordem social e até ambiental, a partir dos projetos globalizados e neoliberais. Se considerarmos o que diz Marx em José Manuel Bermudo (2015), quando fala na alienação no trabalho, veremos o quanto à máquina adquiriu poder e consequentemente impossibilitou o humano a criar e recriar suas 
ideias no sentido amplo. $O$ trabalho coletivo descaracterizou aquilo que antes era controle do indivíduo. Segundo o autor, Marx aponta que a alienação verdadeira está na máquina, como sistema.

O verdadeiro poder é a "máquina", não como instrumento, mas como sistema: o trabalhador assalariado faz parte de um sistema-máquina no qual já não pode criar, improvisar deixar sair a sua alma, mas para o qual tem de contribuir só com o esforço, movimento de seu corpo pautados pelo trabalho em cadeia. (BERMUDO, 2015, p. 44)

E prossegue, acrescentando a seguinte afirmação: "o trabalho assalariado equivale à desumanização do homem, à negação da sua vida conforme a sua essência, a sua condenação a uma vida falsa". (BERMUDO, 2015, p. 45). Entende-se que para contribuir com a estrutura social, um dos órgãos notoriamente regulador, é a educação e seu plano curricular. Plano este, que deve se adequar ao contexto social local e não fugir do global, contribuir com as estruturas família e sociedade. Não seria prudente para a educação, atender aos projetos globalizados e menosprezar o contexto local, ou fazer o oposto disso. É necessário se adequar às duas realidades, um grande desafio.

Se a educação tem a função reguladora na sociedade, cabe a ela uma boa parcela da responsabilidade. É importante lembrar que há outros segmentos sociais que também devem cumprir seu papel de colaborador social e se estes não o fizerem, a educação e o educador vão sobrecarregar. Em (ARENDT, 2007, p. 37): "A distinção entre uma esfera de vida privada e de uma esfera de vida pública corresponde às existências das esferas da família e da política como entidades diferentes e separadas [...]". A citação mostra que o modelo social atual é fruto desta base estrutural que perdura por muitas gerações, mas com o passar dos tempos vem perdendo seu conceito original.

De acordo com a autora, a família deu origem às instituições privadas. Por outro lado, a política deu origem ao público. O fato curioso é quando você reflete sobre cada uma delas e percebe o poder que ambas têm. A base familiar foi e é primordial no equilíbrio 
social. Da mesma forma a política é extremamente importante, por mais que muitos tentam ser apolítico(s). Para entender melhor esta reflexão, sugere-se adentrar nas esferas, política, economia, indústria e tecnológica em seu âmbito globalizado, mas trata-se de um debate muito amplo, porém vamos ficar na superficialidade dos temas no intuito de, mesmo assim, provocar reflexões. Para tanto, a educação como instituição de ensino e a responsável por preparar os cidadãos conscientes de sua função na sociedade deve cumprir seu compromisso sem fugir de ambas as estruturas mencionadas. É por essa razão que vamos considerar o curricular e a didática de ensino no trabalho.

\section{A EDUCAÇÃO}

Ao retornar ao minidicionário Aurélio foi possível ver o que ele diz sobre a palavra educação, trata-se, do: "processo de desenvolvimento da capacidade física, intelectual e moral do ser humano", e ainda, educar é: "promover o desenvolvimento da capacidade intelectual, moral e física de (alguém), ou, de si mesmo". (AURÉLIO, 2000 , p. 251). Se educar é promover o desenvolvimento físico, intelectual e moral do ser humano, fica claro que a família tem extrema importância no processo educacional, como base estrutural. É nela que começam as primeiras relações entre as pessoas. Neste sentido, a justificativa de que deveríamos refletir sobre a família neste artigo e por em evidência a responsabilidade dela como promotora da base na educação dos filhos. Eis uma pergunta a ser feita: a família está atendendo as expectativas que compete a ela?

Entendendo que há outros seguimentos[4] com parte da responsabilidade, cabe a eles, a mesma pergunta. Se a base estrutural está na família e ela cumpre sua função bem como os outros seguimentos, a educação como instituição social pode fazer o complemento para inserir o cidadão na vida em sociedade e capacitá-los para a vida profissional. Entretanto, se a família está com dificuldade em cumprir sua função e da mesma forma, outros seguimentos da sociedade, à escola, não cabe se submeter a fazer o papel de ambos sobrecarregando em suas funções. Para entender a situação, cabe à educação estar atenta ao contexto social, para assim, adequar seu currículo às necessidades do modelo de comunidade a ser atendida. É preciso questionar esse 
modelo, pois a família sustenta a sociedade e é a reproduz as intenções do modelo em vigor.

O curioso é que estamos na era globalizada, dos projetos tecnológicos em expansão e muitas informações. Mas, ao mesmo tempo, a era da globalização, das privatizações, do controle econômico que, direta ou indiretamente, tem interferido nessas estruturas de forma assustadora, e, ainda, uma avalanche de informações que trazem consigo uma série de problemas que são impulsionados pelas distintas informações de grande facilidade no momento. Atualmente há uma competitividade, o desgaste dos cidadãos no mercado de trabalho e, indiretamente, os veículos de comunicação em massa e seus interesses comerciais que estimulam a economia, mas causam uma distorção na base estrutural familiar. Esse reflexo chega à escola $\mathrm{e}$ é um desafio para a educação.

Talvez precisássemos estudar melhor sobre a cultura e a sua influência no social, os riscos da aculturação, é um assunto que exige estudo para outra ocasião. A era da cibercultura, do controle político macroeconômico, das influências diversas, contribuem, mas por outro lado, estão causando uma preocupação em muitas famílias e também na escola, ao lidar com as inovações. A educação escolar, como reguladora social, muitas vezes se sente despreparada para se adequar às influências e inovações tecnológicas. Gosto muito da reflexão em Kemp onde ele fala na "Inserção predominante da intenet e das redes sociais". Dentre as distintas reflexões que o autor proporciona, há uma que chamou-nos a atenção:

Pais, pertence a vocês a responsabilidade de instruir e orientar seus filhos sobre como usar a rede social e os sites com sabedoria. A liberdade ilimitada e a permissividade da sociedade estão totalmente descontroladas, e isso tem resultado em um mal irreparável às famílias. Lembre-se de que a internet pode ser imensamente útil e edificante, mas, certamente, se mal utilizada, prejudicará seus filhos e sua família. Ela não é uma estrada segura para ser trafegada livremente, principalmente por uma criança ou adolescente imaturo, inexperiente e ingênuo. (KEMP, 2013, p. 31). 
Não se pode negar as contribuições do sistema a partir da ideia de globalização. Em contrapartida a sociedade tem sofrido influências que alteram o modo de vida das famílias e seu contexto social. Nem sempre as contribuições são positivas, mas elas passam a fazer parte do cotidiano das famílias e influenciarem no modo de vida delas. Quanto à educação, ela se sujeita a ter que lidar com essa situação e tentar dar respostas a estas mudanças de comportamento da sociedade. A globalização está presente e é uma experiência que funciona, principalmente para a economia, para os projetos políticos e ideológicos. Mais, para que haja um equilíbrio que atenda às necessidades da população é preciso ação de uma sociedade civil consciente, composta pelo conjunto[5] das influências sociais e principalmente da família. Se esta última não exercer sua função, o caos social pode ser promissor. Perdoe-nos parecer pessimista!

Neste sentido, cabe à educação se reorganizar para sobreviver em meio às constantes inovações tecnológicas. É necessário e urgente um modelo educacional que atenda as exigências do mercado competitivo e pragmático do momento. Assim sendo, é que entra a necessidade da reflexão sobre a estrutura Curricular da escola. Refletindo em consonância com Arendt, citada acima, atualmente o público está transformando em privado e o privado que deveria seguir sua origem, está perdendo a essência em função do econômico. Se a origem do privado está na base familiar e esta perde a sua essência, por sua vez, o público, que vem da polis e tem como função controlar e proteger o social age da mesma forma. É essencial que a educação ajude na regulação destes princípios.

Quando se tem uma consciência, é difícil aceitar alguém ditando as regras para a sua família e dentro da sua casa. O que se tem de concreto nos últimos tempos é um sistema ditando os interesses econômicos dentro do contexto familiar e também no social. Há indícios de que os mecanismos de controle social que nasceram para proteger as famílias estão sendo controlados pelas grandes corporações de ordem econômica, muitas vezes, por intermédio dos veículos de comunicação globalizados. Este é um desafio que a educação deve se atentar e adequar seu currículo para 
valorizar o que é útil à sociedade e despertar, ou instruir as famílias sobre os excessos do sistema.

\section{O CURRÍ́CULO}

Procurando uma definição para o termo currículo, encontramos em (KAMMIS, 1993), em El Curriculum, autores que definem o currículo em distintas situações. Há os que dão maior ênfase ao assunto e outros são menos exigentes. Para facilitar a compreensão do leitor, retiramos duas citações para reflexão. Parece-nos que, para autor, o centro do estudo do currículo é um vazio entre ideias e aspirações, no entanto, em Stenhouse há outra perspectiva, a de que o interesse central do estudo do currículo é a adequação de práticas e propostas. Veja citação:

JOHNSON (1967) lo define como "una serie estructurada de resultados buscados en el aprendizaje", mientras KEARNEY y COOK (1969) lo describen como "todas las experiencias que el estudiante lleva a cabo bajo la tutela de la escuela". En general, LAWTON (1973) señala un movimiento que va desde las perspectivas más antiguas del curriculum, que restringían el uso del término al contenido impartido, hacia otra más reciente en la que el término engloba todos los aspectos de la situación enseñanza/aprendizaje (CODD, 1984, p. 8) . De manera semejante, algunos autores tratan de incluir la noción de curriculum "oculto" (JACKSON, 1968; ORMELL, 1979) en el ámbito de sus definiciones, mientras otros (como JOHNSON, op. cit.) prefieren limitar sus definiciones al curriculum "oficial" de la escuela. (KEMMIS, 1993, p. 10)

Percebe-se que são distintas opiniões sobre a função do currículo. Cabe ao leitor, ou à educação escolher o que melhor lhe convir. Mas a citação veio no sentido de ilustrar as possíveis possibilidades, não se pretende dialogar sobre elas aqui. Viu-se logo no início do livro de (KEMMIS, 1993), que havia ali a preocupação com uma teoria curricular para atender a demanda contemporânea e procuramos citá-la a seguir. (KEMMIS, 1993, p. 3): "Necesitamos una teoría más poderosa del curriculum que nos permita efectuar mejores análisis de la naturaleza y efectos de los curriculos 
contemporáneos y actuar más adecuadamente sobre la base de lo que conocemos". É preciso ser audacioso na busca por aprimorá-lo, pois a realidade requer inovações, requer adequação à nova realidade que é promissora, mas também vulnerável.

Estamos em uma nova realidade que exige uma estrutura curricular adequada para o momento. O mundo moderno, globalizado, traz desafios constantes. Para atender aos anseios da população, a educação tem que se estruturar para dar suporte às exigências do mundo em constante evolução. Não há como fugir desta realidade, pelo contrário, a educação tem que adequar seu currículo e propor, didaticamente uma visão crítica sobre os efeitos destas mudanças estruturais. Pensando assim, Kemmis (1993), alerta para novas teorias. Um currículo que permite maior reflexão e análise de seus efeitos, um currículo com perfil do mundo contemporâneo, que venha atuar adequadamente atendendo o momento. Não se pode omitir carência da educação por inovação.

Olhando por outra dimensão, buscamos trazer para reflexão o pensamento de Thurler e nele, também é perceptível a necessidade de ajustes. A autora fala no desenvolvimento de competências para o aluno ultrapassar obstáculos na construção de novos saberes. É preocupante perceber que para desenvolver tais competências, precisa-se de um professor dinâmico, capaz de ultrapassar obstáculos na construção dos saberes. Esse professor deve ter uma postura crítica e inovadora para atender as necessidades do público onde está inserido. Portanto, como se pode ver, é preciso ler e refletir sobre o que propõe a citação abaixo.

[...] os novos objetivos de aprendizagem levam em conta o desenvolvimento de competências. "A experiência mostra que os alunos só aprendem quando enfrentam situações didáticas em que são obrigados a ultrapassar obstáculos e a construir novos saberes, consolidando suas aquisições. (THURLER. IN. ELABORAÇÃO DE PROJETOS: GUIA DO CURSISTA, 2009, p. 99).

Depois de observar a opinião da autora, sugere-se ao leitor adentrar em outro referencial que afirma, segundo suas autoras, dar suporte ao que estamos discutindo 
até aqui. Nesse sentido, "Metodologias Ativas para uma educação inovadora: uma abordagem teórico-prática (2018)" possibilitou-nos retirar informações que parecem pertinentes. Pois, ao falar na educação em uma perspectiva inovadora Bacich e Moran juntamente com os seus colaboradores, trazem experiências que garantem direcionar a educação numa perspectiva que venha a atender a demanda do momento. A obra fala na complexidade atual e aponta a construção do processo entre três movimentos: o individual, o grupal e o tutorial. Portanto, é sugestiva a leitura dessa obra ao interessado em aprimorar conhecimento dentro do assunto.

Metodologias ativas são estratégias de ensino centradas na participação efetiva dos estudantes na construção do processo de aprendizagem, de forma flexível, interligada e híbrida. As metodologias ativas, num mundo conectado e digital, expressam-se por meio de modelos de ensino híbridos, com muitas possíveis combinações. A junção de metodologias ativas com modelos flexíveis e híbridos traz contribuições importantes para o desenho de soluções atuais para os aprendizes de hoje. (MORAN. IN. BACICH E MORAN, 2018. p 4)

Acredita-se que nem todos os atores da educação estão aptos a estas mudanças. São necessários ajustes constantes fazendo com que os profissionais, no caso, profissionais da educação, obviamente, se adeque constantemente. Os desajustes na estrutura familiar é uma consequência social e dessa forma traz comprometimento ao profissional da educação que muitas vezes deixa de atender ao seu compromisso de educador para suprir a carência familiar do aluno, dando-lhe orientações básicas que é função da família. Entende-se que as constantes mudanças de comportamento da sociedade, muitas vezes impulsionadas pelos veículos de comunicação, tem gerado um caos social. O bombardeio de informações nem sempre contribui naquilo que é necessário na ajuda à família e à escola, esta última, responsável por fazer a mediação entre o Estado e a sociedade civil. .

Considerando a reflexão de Thuler, citada anteriormente no artigo, existem professores incertos sobre os efeitos dos seus ensinamentos. Esta é uma situação bastante preocupante. Considerando o nível de desenvolvimento no Brasil, tanto o 
econômico, o social e consequentemente o intelectual, fica esclarecida a imaturidade na capacitação profissional de muitos professores. Há rumores na região[6], que muitos professores desafiaram a dar aula sem mesmo terem uma formação Básica. A formação superior de muitos professores é algo recente. A geração de professores da atualidade, ainda é fruto destes bravos lutadores em prol da educação que iniciaram o processo em condições que só os mesmo eles conseguem definir.

A maioria dos professores não têm certeza se seu ensino produz realmente a aprendizagem desejada e confiam cegamente na sua capacidade de programação didática e na validade de seu sistema de avaliação; ou se fecham em uma atitude mais resignada e até mesmo cínica diante da dificuldade de fazer com que seus esforços correspondam a efeitos reais e palpáveis. (THURLER. IN. ELABORAÇÃO DE PROJETOS: GUIA DO CURSISTA, 2009, p. 100).

Enquanto o mundo moderno se inventa e reinvente a cada dia, uma boa parcela da educação e também de educadores estão se descobrindo. Há profissionais que não percebem a importância do currículo, da mesma forma, é o entendimento de que educação deve se adequar ao contexto social em que está inserida. É preocupante saber que o mundo globalizado, controlado por grandes corporações em nível econômico e político, restringe-se aos interesses empresariais em caráter industrial e esquece a população civil. Tais influências se dedicam em construir um conceito de cultura nos moldes e interesses das grandes corporações e estão destruindo "fortificações" locais no âmbito da família e da comunidade.

Se, é verdade que o poder público, um mecanismo que nasceu para proteger as famílias e a sociedade está sendo corrompido. Também é verdade que está havendo distorções no seio familiar, portanto, é importante refletir sobre a necessidade da educação como reguladora das ações no Estado. Pensar em uma concepção curricular que desperte intelectuais capazes de encontrar alternativas protetoras para este mesmo Estado e consequentemente para a família que é a população civil. É preciso que o diálogo em torno das inovações, que são importantes, encontre alternativas para sanar muitos desmandos da era moderna. A razão foi a base 
inspiradora desta nova era e é imprescindível encontrar, a partir dela, soluções de forma racional que dê suporte a tais mudanças sem levar o Planeta Terra e a humanidade ao caos.

\section{A EDUCAÇÃO PARA O FUTURO}

Ao pensar no futuro, deve-se olhar ao passado e tentar compreender as mudanças estruturais que a sociedade obteve nos últimos tempos. No mínimo, voltar ao início dos projetos liberais, do sonho de uma sociedade livre e promissora. Um mundo em que o indivíduo deixasse de ser explorado e pudesse sonhar com o potencial racional da espécie humana. É verdade que muito se construiu com o advento do mundo moderno e tecnológico, uma grande revolução aconteceu, assim como é verdade e é preciso estar claro que o mundo sonhado não é esse que estamos vivendo na contemporaneidade. Acredita-se que as mudanças ocorridas no neoliberalismo ampliou o descrédito rumo à liberdade esperada, talvez tenhamos que classificar este momento como o período da carência afetiva, do estresse e das depressões, infelizmente.

Ao ler o livro "Raízes da Depressão: Enfrentando o grande mal do século (2017)," encontramos um dos títulos que trata da falta de objetividade na vida. Refere-se, no entanto sobre a "A crise existencial". Por mais que a obra tem seu viés voltado ao espiritual, e, não queremos discuti-lo aqui, entendemos as opiniões do autor como promissoras e de bastante sentido, pois a falta de iniciativa para se tomar uma decisão produzem no indivíduo humano angústias, uma ansiedade que, além de atingir o outro, ele que é o sujeito, também sai muito prejudicial, e ainda, é prejudicial às outras pessoas do seu círculo de convívio. Segundo o autor, a direção é um desejo inato do ser humano e você verá isso na citação abaixo. Espera-se ela sirva como mecanismo para ajudar no que estamos refletindo até aqui.

Todo ser humano carrega consigo um desejo inato de possuir direção e propósito de vida. Aqui reside um dos maiores segredos da saúde emocional. Ter uma razão para viver afeta diretamente a nossa qualidade de vida. Todos nós temos uma direção vocacional a seguir. 
Esse senso de destino é como uma bússola que nos orienta no vasto território definido pelo serviço especializado que podemos prestar a outros, preenchendo, assim, o significado da nossa existência. (BORGES, 2017, p 101).

Em outra dimensão, Marx, segundo Bermudo (2015) fala na alienação. Na opinião apresentada pelo autor vimos que: “... A alienação do trabalho assalariado é atravessada pelo paradoxo de todos os tipos de alienação: quanto mais poderoso é o objeto..." e acrescenta: “... seja este Deus, o Estado ou a Mercadoria, mais insignificante e miserável é o ser humano, maiores são sua servidão e sua submissão. ..." (BERMUDO, 2015, p. 44). Talvez esteja aí uma explicação para a falta de objetividade das pessoas. Somos uma nação que prega a "democracia" dizendo que "muito se pode", mas na realidade, poucos adquirem o que almejam alcançar. Se analisarmos minuciosamente, é possível perceber que passamos de uma situação de domínio forçado a um domínio muito discreto, quase oculto. Trata-se do domínio ideológico, para Marx, segundo Bermudo: um ser alienado. Estamos falando em uma sociedade em que as pessoas acreditam ter a liberdade para falar, mas tirara-Ihes a razão, a capacidade ideológica de pensar dentro da necessidade, do contexto de sociedade em que se vive.

Atualmente temos poderes, o Poder Público, as Instituições e a Sociedade Civil. Ambos têm seus interesses e, para atender a especificidade de cada um, é prudente que a educação seja planejada, articulada com muito carinho e em conjunto. Não dá para atender a um seguimento e menosprezar o outro. Se presenciássemos um iluminista que tanto sonhou com a liberdade, é bastante provável que ele pedisse à humanidade para não perder a razão. Graças à luta de muitos pensadores, inclusive da educação, a educação vem ganhando novos horizontes, apesar de saber que ela está num patamar inferior às perspectivas sonhadas, portanto, não há, tem muito a se fazer.

O educador é preparado para repassar suas experiências, mas geralmente segue as orientações do projeto de sociedade em vigor. Por mais que busca fazer o melhor, ele está sujeito a erros e acertos bem como a imposição de uma hierárquica que inibi o 
nível de criticidade do mesmo. Felizmente, há pessoas que possuem um grau de instrução e defende, com toda sabedoria o profissional da educação. Para justificar o que estamos falando, vamos apresentar uma citação buscada em um personagem que nem é desta área de conhecimento, mas é muito bem aceito em vários países do mundo por suas produções, relato das experiências como psicólogo e psiquiatra. Estamos falando em Augusto Cury.

"Ninguém é tão importante como os professores no teatro social, embora a débil sociedade não lhes dê a importância que merecem." Todo o profissional, em qualquer profissão ou instância social que exerça, passa pela sala de aula e tem orientações de um professor, mas nem todos reconhecem a importância dele. (CURY, 2014, p. 15).

A sociedade atual tem vivido pressões em função da globalização e gerado um estresse social muito grande, situação mencionada em outro momento no artigo. $O$ professor, direta ou indiretamente, tem sofrido esse desgaste pelas ações dos alunos e até mesmo dos pais. Trata-se de reflexos que se inicia na família, na relação entre pais e filhos, mas chegam à escola e atinge o professor que também possui uma família, e, portanto, vive as mesmas pressões, tanto interna, como também externa. Alguns professores se sentem desmotivados, soma-se a isso, o desgaste no trabalho e tem como resultado, o estresse. Na verdade se tem muitas informações, pouca capacitação profissional em muitos casos e diversas cobranças que são evidentes.

A pressão psicológica, o despreparo profissional e consequentemente a falta de alternativas, faz gerar o caos. Como mostra (CURY, 2014, p. 16): "Se fôssemos piloto de avião, a melhor conduta talvez fosse desviarmo-nos das formações densas de nuvens, mas, como pilotos mentais, essa seria a pior atitude, embora seja a comumente adotada." Há um controle social determinado por grandes corporações e interesses restritos que não atende à demanda social, reduz a autoestima e produz um caos social, que segundo Cury, não é a melhor alternativa.

Por outro lado, em Pedagogia da Autonomia, (FREIRE, 2004, p. 93/94), chama atenção do professor para uma responsabilidade: “... O professor que não leve a sério 
sua formação, que não estude, que não se esforce para estar à altura de sua tarefa não tem força moral para coordenar as atividades de sua classe...". Parece que Freire acerta ao pedir ao professor o compromisso para levar a sério a sua formação. Tudo o que foi refletido até aqui está nesta direção, a de aprimorar conhecimento, atualizar e buscar alternativa. Nada melhor que o sentimento de superação, uma sensação oposta ao conceito de depressão tanto discutida neste artigo. E acrescenta: “... a incompetência profissional desqualifica a autoridade do professor.". (FREIRE. 2004, p 94). Evidentemente!

Cada vez mais vivemos numa rotina sufocante. Levantamos da mesma maneira, reclamamos dos mesmos problemas, cumprimentamos as pessoas da mesma forma, corrigimos os filhos, alunos e colegas de trabalho com os mesmos jargões, andamos pela mesma rua, possuímos os mesmos desejos. Enfim, dançamos a valsa da vida com as duas pernas engessadas. (CURY, 2007, p. 74/75).

E ainda:

O Canadá, onde escrevo este livro, é um dos países de melhor qualidade de vida do mundo. Porém, essa qualidade de vida é material e não emocional. As leis fundamentais da psicologia para se ter qualidade de vida proposta neste programa têm sido, como em todas as demais sociedades, desrespeitadas. (CURY, 2007, p. 47).

O modelo econômico e o político neoliberal entende a liberdade de uma forma que não condiz com o interesse real, trata-se de uma liberdade que está oculta. Só a alcança, quem a ela se adapta, na realidade, o que se vê, são os laços familiares deteriorando e dando lugar a um diálogo mecânico e globalizado através das mídias sociais onde o virtual supera o real. A rotina de trabalho ocupa um tempo das pessoas, as redes sociais, outro, e os laços afetivos familiar estão enfraquecendo. Esta é a realidade mais fortemente presente! 
Sugere-se que os Centros de Formação (Universidades) preparem os cursos de formação adaptando-os aos novos tempos. Dentro do que foi refletido até aqui está evidente que as inovações tecnológicas estão impulsionando a demanda na formação dos profissionais da educação. O problema está em acompanhar a evolução. Enquanto a educação dá um passo rumo à inovação, a indústria tecnológica se especializa em uma dimensão inigualável. Para ter uma dimensão do que estamos falando, encontramos a informação de que: “... o dia 7 de setembro de 1922 marcou a primeira transmissão de rádio no país que ocorreu simultaneamente à exposição internacional em comemoração ao centenário da independência do Brasil... (VIRGíLIO, 2012): Estamos falando no início da influência da comunicação no país, uma experiência "jovem" se comparada aos mais 500 de sua existência.

E segundo a enciclopédia livre - Wikipédia: "A televisão no Brasil tem início comercialmente em 18 de setembro de 1950, quando foi inaugurada a TV Tupi em São Paulo, com equipamentos trazidos por Assis Chateubriand, fundando assim o primeiro canal de televisão no país". Mais jovem ainda, é a televisão, porém a sua eficácia superou a primeira. Quando analisada de forma crítica, se percebe que ao informar a população, e isso é muito positivo, também se encontra sobre ao seu poder, a capacidade de "adestrar" a sociedade e desta vez, com duas possibilidades: a associação da audição com a visão envolvendo situações reais, mas também fictícias. Entretanto, a evolução não parou por aí, podendo ser considera "uma criança ainda", mas em dimensão avassaladora, aparece a internet. Foi a partir desta última que os riscos ampliaram. Sugere-se que a educação não procure evitar esta realidade, também, não condená-la em sua eficácia, mas deve-se apropriar dos valores e recursos disponíveis que ela possui e assim, instruir os alunos na mesma direção.

Em (R7. 2009 - RNP na mídia) viu-se que:

O primeiro acesso à internet propriamente dita só foi acontecer em 1991, quando a Fapesp começou a transmitir dados por meio do protocolo TCP/IP, que é o padrão nessa rede - o protocolo, usado em todas as conexões à web, permitindo que as máquinas "falem a mesma língua" e possam trocar informações entre si. 
A citação acima, mostra com clareza a origem desta ultima façanha. Se fôssemos ampliar a lógica do raciocínio rumo à evolução, entraríamos em outro fenômeno da atualidade, a corrida espacial. Fiquemos por aqui. $\mathrm{O}$ importante é refletir que, como consequência destes avanços, também entra em jogo o debate em torno da questão ambiental e, em se tratando do Brasil, o debate sobre a Amazônia é promissor. A educação que tem como dever orientar os cidadãos da sociedade e está com dificuldades em adaptar o currículo às inovações que estão presentes, deveria já estar pensando nos avanços que estão sendo projetado, bem como, estar se preparando para debater sobre as consequências que a humanidade pode sofrer com as novas influências. Estes últimos desafios podem tornar a situação futura muito grave e a tecnologia não dar conta de contorná-la.

Para José Moran "As pesquisas atuais da neurociência comprovam que o processo de aprendizagem é único e diferente para cada ser humano, e que cada pessoa aprende o que é mais relevante e o que faz sentido para si, o que gera conexões cognitivas e emocionais. (MORAN. IN. BACICH E MORAN, 2018, p. 2). E considerando a reflexão de Marcelo Ganzela, no mesmo livro, "há três possibilidade do uso das tecnologias no ensino de literatura": "lidar com as tecnologias", "usá-las como ferramenta de interação" e explorá-las como ferramenta para construção/ produção de novos conhecimentos". (GANZELA. IN BACICH E MORAN, 2018, p. 51. Se há diferenças na aprendizagem e tantas possibilidades, como mostram os autores, é preciso sonhar com as alternativas para sanar as necessidades expostas até aqui.

A denúncia de uma crise de sentido na educação não é algo novo e exclusivo do momento histórico em que vivemos. Podemos dizer que a crítica ao modelo educacional é à função social da escola se constituir à medida que a própria educação se institucionaliza, incorporando a responsabilidade de ser um processo sistemático e intencional de formação humana. (ROCHA. IN. BACICH E MORAN, 2018, p. 154).

Espera-se que as reflexões apresentadas neste artigo sejam entendidas como um aceno à educação para que a escola exerça a sua função, como explicita Rocha na citação acima, caso contrário, pouco estaríamos fazendo. A dedicação a este trabalho 
exigiu muitas buscas, a grande expectativa é a de que o mesmo sirva como fomento ao debate que envolva a educação e a adequação do currículo aos novos tempos. empenho nele dedicado visou trilhar por esta "colcha de retalhos" que é a educação e seus instrumentos de ensino/aprendizagens. Assim sendo, encerra-se o diálogo aqui, resta-nos a expectativa de que ele provoque outras reflexões em torno da temática proposta.

\section{CONSIDERAÇÕES FINAIS}

Depois de descrever distintas possibilidades pertinentes ao resumo inicial deste artigo, introduzimos o assunto e caminhamos passo a passo na direção final da produção. Espera-se que o Tema: Educação e Currículo: Como atender a demanda no contexto social atual, tenha contribuído proporcionando muitas reflexões ao leitor. Trata-se de um assunto, na realidade, muito amplo e polêmico, no entanto, um tema promissor. Feito estes primeiros ajustes, passou-se a descrever as possíveis situações que norteassem o raciocínio proposto. A partir dos referenciais estudados e citados no trabalho, buscou-se conciliação ideias e fazer as críticas frente a uma realidade que todos sabemos, mas poucos conseguem desvendá-la, trazendo para a realidade inovações consistentes.

Deve estar esclarecido que pensar e descrever a importância e eficácia da adaptação de um bom currículo para a educação, não é uma tarefa fácil. O momento político e ideológico de tantas incertezas exige uma transição no cenário brasileiro, mas também, global que a educação tem tido muitas dificuldades para si adaptar. A educação, em sua essência, deve trabalhar as ideias curriculares, mas também as técnicas pertinentes ao mundo do trabalho. Às vezes a educação é crítica e em outros momentos se neutraliza e acompanha as ações e reações no cenário social. A situação mais preocupante no momento, é que o cenário político brasileiro atual, tem demonstrado muitas incertezas, dificultando, ainda mais, a ação da educação. Por essa razão, o estudo em evidência fez referência à família, à educação, e por fim, ao currículo, para pontuar possíveis alternativas que direcione a educação rumo a um futuro mais promissor. 
Ao fim das reflexões expostas até aqui, ficou a certeza e o convite aos profissionais da educação na expectativa da adequação dos seus currículos à nova realidade. É preciso que a educação se sinta forte e acredite no seu potencial, para, enfim, suprir as incertezas dos projetos sociais não condizentes com a realidade. A educação tem que ser uma instituição sonhadora, persistente e sempre ter como meta a aprendizagem dos seus alunos de forma crítica. Deve proporcionar sonhos e realizações.

\section{REFERÊNCIAS}

ALVES, Rubem. A Alegria de Ensinar. Ed. ARS Poéticas LTDA. Ed. 3. 1994.

ARENDT, Hannah. A condição Humana. Tradução de Roberto Raposo. Prefácio de Celso Lafer. 10ํed. Rio de Janeiro. Forense Universitária, 2007.

BACICH, Lilian. MORAN, JOSÉ. Metodologias ativas para uma educação inovadora: uma abordagem teórico-prática. Porto Alegre. Penso, 2018.

BERMUDO, José Manuel. Marx - Da ágora ao mercado. São Paulo. Salvat, 2015.

BORGES, Marcos de Souza. Raízes da Depressão: enfrentando o grande mal do século. Paraná. Jocum, 2017.

CURY, Augusto. Coleção - Sonhos e disciplina. Transforme seus projetos em realidade. São Paulo. Gold, 2014.

Augusto. 12 semanas para mudar uma vida. São Paulo. Planeta do Brasil, 2007.

FERREIRA, Aurélio Buarque de Olanda. Minidicionário da Língua Portuguesa. Rio de Janeiro. Nova Fronteira, 2000.

FREIRE, Paulo. Pedagogia da Autonomia. Paz e Terra, 2004. 
KEMP, Jaime. Pai inteligente influencia filho adolescente - Se você não faz, alguém o fará. Rio de Janeiro. Graça, 2013.

KEMMIS, Sthephen. El Curriculum: más Allá de una Teoría de Lá Reproducción. Morata. Madrid, segunda edição, 1993.

MAÇAL, Jéssica. Discurso no Vaticano. Disponível em < http://papa.cancaonova.com/papa-reitera-valor-da-familia-e-diz-nao-a-conceitosideologicos/ > Acesso em 21 mar. 2016.

RNP. Rede Nacional de Ensino e Pesquisa: promovendo o uso inovador de redes $\begin{array}{llll}\text { avançadas no } & \text { Brasil. } & \text { Disponível }\end{array}$ https://memoria.rnp.br/noticias/imprensa/2009/not-imp-09-09-27a.html > Acesso em: 28 jan. 2020.

THURLER, Mônica Gather. Currículo. Formação de professores numa escola aprendiz. In: Elaboração de projetos: guia do Cursista. PRADO, Maria Elisabette Brisola Brito. ALMEIDA, Maria Elizabeth Biancocini de. (Organizadoras). ed.1. Brasília: Ministério da Educação, Secretaria de Educação à Distância. Brasília, 2009.

VIRGÍlIO, Paulo. Agência Brasil. Primeira transmissão de rádio no Brasil completa 90 anos. Criado em 07/09/2012 e atualizado em 07/07/2016. Disponível em < http://noticias.uol.com.br/ciencia/ultimas-noticias/redacao/2015/10/02 > Acesso em 29/01/2020.

\section{APÊNDICE - REFERÊNCIAS DE NOTA DE RODAPÉ}

2. TDIC - Tecnologias digitais de informação e comunicação.

3. Grandes corporações entendidas como as empresas de tecnologias nacional, multinacionais ou transnacionais da era globalizada.

4. A religião, sindicato, associativismo, cooperativismo e até os veículos de comunicação de massa. 
5. Entende como conjunto os vários seguimentos sociais encarregados da educação, como: igrejas, associações, entidades sindicais, dentre outros.

6. Região Norte do país onde o artigo está sendo produzido, mais especificamente em Rondônia.

Enviado: Dezembro, 2018.

Aprovado: Março, 2020. 